\title{
Aerosol effects on ice clouds: can the traditional concept of aerosol indirect effects be applied to aerosol-cloud interactions in cirrus clouds?
}

\author{
S. S. Lee and J. E. Penner \\ Department of Atmospheric, Oceanic, and Space Sciences, University of Michigan, Ann Arbor, MI, USA \\ Received: 19 January 2010 - Published in Atmos. Chem. Phys. Discuss.: 21 April 2010 \\ Revised: 18 October 2010 - Accepted: 2 November 2010 - Published: 4 November 2010
}

\begin{abstract}
Cirrus clouds cover approximately 20-25\% of the globe and thus play an important role in the Earth's radiation budget. Therefore the effect of aerosols on cirrus clouds can have a substantial impact on global radiative forcing if either the ice-water path (IWP) and/or the cloud ice number concentration (CINC) changes. This study examines the aerosol indirect effect (AIE) through changes in the CINC and IWP for a cirrus cloud case. We use a cloud-system resolving model (CSRM) coupled with a double-moment representation of cloud microphysics. Intensified interactions among CINC, deposition and dynamics play a critical role in increasing the IWP as aerosols increase. Increased IWP leads to a smaller change in the outgoing LW radiation relative to that for the SW radiation for increasing aerosols. Increased aerosols lead to increased CINC, providing increased surface area for water vapor deposition. The increased deposition causes depositional heating which produces stronger updrafts, and leads to the increased IWP. The conversion of ice crystals to aggregates through autoconversion and accretion plays a negligible role in the IWP response to aerosols, and the sedimentation of aggregates is negligible. The sedimentation of ice crystals plays a more important role in the IWP response to aerosol increases than the sedimentation of aggregates, but not more than the interactions among the CINC, deposition and dynamics.
\end{abstract}

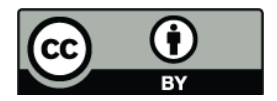

Correspondence to: S. S. Lee (seoungl@umich.edu)

\section{Introduction}

Aerosols act as cloud condensation nuclei (CCN) and thus affect cloud properties. Increasing aerosol mass and number are known to decrease droplet size and thus increase cloud albedo (first AIE) (Twomey, 1974, 1977). They may also suppress precipitation and, hence, alter cloud mass and lifetime (second AIE) (Albrecht, 1989). An enormous effort has gone into trying to understand the effect of aerosols on clouds, since these effects have been considered to be critical for the correct assessment of the climate change induced by human activities (Penner et al., 2001).

The aerosol indirect effect was proposed based on observational and modeling studies of warm stratiform clouds (Twomey, 1977; Albrecht, 1989) and most climate studies have focused on the effect of aerosols on warm stratiform clouds for the prediction of climate change.

Lee et al. (2009) showed that aerosols can lead to significant changes in the top of the atmosphere (TOA) longwave and shortwave radiation through their effects on cirrus clouds. Cirrus clouds cover approximately $20-25 \%$ of the globe and as much as $70 \%$ of the tropics and, thus, can act as a major modulator of the global radiation budget (Liou, 1986, 2005). Hence, the effect of aerosols on cirrus clouds may have contributed to changes in the global radiation budget and to climate change as a result of increased emissions from industrialization and biomass burning.

Lee et al. (2009) focused on cirrus clouds detrained from deep convective clouds. The radiative properties of these clouds are mainly determined by ice-crystal formation and growth in deep convective clouds (Houze, 1993). About half of the large-scale cirrus clouds have their origins in the

Published by Copernicus Publications on behalf of the European Geosciences Union. 
upper layers detrained from deep, precipitating cloud systems (Houze, 1993). The other half has their origins in largescale vertical motions, with velocities much smaller than the vertical velocity in deep convective clouds. Different dynamic intensity (i.e., vertical velocity) is likely to lead to different interactions between microphysics and dynamics by affecting the magnitude of deposition and sublimation. Hence, the properties of cirrus clouds and thus the effects of aerosols on clouds with weak large-scale motions are likely to be different from those coupled to strong deep convective motion.

In this study, the effect of aerosols on cirrus clouds developing as a result of large-scale low velocity vertical motion is examined using a CSRM.

\section{CSRM}

\subsection{Dynamics and turbulence}

For numerical experiments, the Goddard Cumulus Ensemble (GCE) model (Tao et al., 2003) is used as a three-dimensional nonhydrostatic compressible model. The detailed equations of the dynamical core of the GCE model are described by Tao and Simpson (1993) and Simpson and Tao (1993).

The subgrid-scale turbulence used in the GCE model is based on work by Klemp and Wilhelmson (1978) and Soong and Ogura (1980). In their approach, one prognostic equation is solved for the subgrid-scale kinetic energy, which is then used to specify the eddy coefficients. The effect of condensation on the generation of subgrid-scale kinetic energy is also incorporated into the model.

\subsection{Microphysics and radiation}

To represent microphysical processes, the GCE model adopts the double-moment bulk representation of Saleeby and Cotton (2004). The size distribution of hydrometeors obeys a generalized gamma distribution:

$n(D)=\frac{N_{\mathrm{t}}}{\Gamma(v)}\left(\frac{D}{D_{\mathrm{n}}}\right)^{v-1} \frac{1}{D_{\mathrm{n}}} \exp \left(-\frac{D}{D_{\mathrm{n}}}\right)$

where $D$ is the equivalent spherical diameter (m) (for ice crystals, $D$ is the crystal maximum dimension), $n(D) d D$ the number concentration $\left(\mathrm{m}^{-3}\right)$ of particles in the size range between $D$ and $D+d D$ and $N_{\mathrm{t}}$ the total number of particles $\left(\mathrm{m}^{-3}\right)$. Also, $v$ is the gamma distribution shape parameter (non-dimensional), $D_{\mathrm{n}}$ is the characteristic diameter of the distribution $(\mathrm{m})$, and $\Gamma(v)$ the complete gamma function of $v$.

Feingold et al. (1988) found full stochastic collection solutions for self-collection among cloud droplets (or cloud liquid) and ice crystals (or cloud ice) and for the collection of cloud droplets and ice crystals by precipitable hydrometeors using realistic collection kernels and these are adopted here; there are five classes of precipitable hydrometeors, which include rain, snow, aggregates, graupel, and hail. Hence, this study does not constrain the system to constant or average collection efficiencies. Following Walko et al. (1995), lookup tables are generated and used in each collection process. This enables fast and accurate solutions to the collection equations. In this study, snow is treated as a part of cloud ice or ice crystals, since snow is defined as ice crystals that grow by deposition to larger than $125 \mu \mathrm{m}$ in the maximum dimension in the bulk representation of Saleeby and Cotton (2004). Simulations described in the following sections show that cloud mass in the simulated cirrus clouds is composed only of cloud ice, snow and aggregates. For cloud ice, snow, and aggregates, $v\left(D_{\mathrm{n}}\right)$ is $0.18(20 \mu \mathrm{m}), 0.18(400 \mu \mathrm{m})$, and $0.5(400 \mu \mathrm{m})$, respectively.

A bin representation of collection is adopted for the calculations of hydrometeor sedimentation. Bin sedimentation is simulated by dividing the gamma distribution into discrete bins and then building lookup tables to calculate how much mass and number in a given grid cell falls into each cell beneath a given level in a given time step. 36 bins are used for collection and sedimentation. This is because Feingold et al. (1999) reported that the closest agreement between a full bin-resolving microphysics model in a large eddy simulation (LES) of marine stratocumulus cloud and a bulk microphysics representation was obtained when collection and sedimentation were simulated by emulating a full-bin model with 36 bins.

All the cloud species here have their own terminal velocity. The terminal velocity of each species is expressed as power law relations (see Eq. 7 in Walko et al., 1995). A Lagrangian scheme is used to transport the mixing ratio and number concentration of each species from any given grid cell to a lower height in the vertical column, following Walko et al. (1995).

The parameterizations developed by Chou and Suarez (1999) for shortwave radiation and by Chou et al. (1999), and Kratz et al. (1998) for longwave radiation have been implemented in the GCE model. The solar radiation scheme includes absorption due to water vapor, $\mathrm{CO}_{2}, \mathrm{O}_{3}$, and $\mathrm{O}_{2}$. Interactions among the gaseous absorption and scattering by clouds, molecules, and the surface are fully taken into account. Reflection and transmission of a cloud layer are computed using the $\delta$-Eddington approximation. Fluxes for a composite of layers are then computed using the two-stream adding approximation. In computing thermal infrared fluxes, the k-distribution method with temperature and pressure scaling is used.

For the radiative properties of cloud ice, a generalized effective size is inferred from the mean $(\langle\rangle)$ size of the equivalent spherical diameter $\left(D_{\mathrm{i}}\right)$ with a look-up table for $\frac{D_{\mathrm{ge}, \mathrm{i}}}{\left\langle D_{\mathrm{i}}\right\rangle}$, where $D_{\mathrm{ge}, \mathrm{i}}$ is a generalized effective size of cloud ice. This look-up table was generated by integrating numerically the formula for the generalized effective size of cloud ice given by $\mathrm{Fu}$ (1996) for a range of values of $\left\langle D_{\mathrm{i}}\right\rangle$. Crystals are 
assumed to be columnar (McFarquhar et al., 1999) with a ratio of length to width, $L / D$, specified from aircraft observations (Ono, 1969; Auer and Veal, 1970) in the manner of $\mathrm{Fu}$ and Liou (1993), which obeys a gamma size distribution. Note that the assumption of columnar crystals is applied only for the radiative properties of cloud ice. The axial ratio varies between 1 and almost 5 for $D$ varying from 20 to $160 \mu \mathrm{m}$.

\subsection{Ice nucleation}

Lohmann and Diehl's (2006) parameterizations, taking into account the dependence of ice nuclei (IN) activation on dust and black carbon (BC) aerosol mass concentration, are used for contact, immersion, and condensation-freezing activation of IN. For contact activation:

$$
\frac{d N_{\mathrm{CNT}}}{d t}\left(\mathrm{~m}^{-3} \mathrm{~s}^{-1}\right)=m_{\mathrm{io}} D_{\mathrm{ap}} 4 \pi r_{\mathrm{cm}} N_{\mathrm{a}, \mathrm{cnt}} \frac{\rho_{\mathrm{a}} n_{\mathrm{c}}}{\bar{m}_{\mathrm{c}}}
$$

where $\frac{d N_{\mathrm{CNT}}}{d t}$ is the rate of the production of ice-crystal number concentration via contact freezing, $m_{\text {io }}\left(10^{-12} \mathrm{~kg}\right)$ is the initial mass of a newly formed ice crystal, $D_{\text {ap }}\left(\mathrm{m}^{2} \mathrm{~s}^{-1}\right)$ is the Brownian aerosol diffusivity, $r_{\mathrm{cm}}(\mathrm{m})$ is volume-mean droplet radius, $N_{\mathrm{a}, \mathrm{cnt}}\left(\mathrm{m}^{-3}\right)$ is the number concentration of contact nuclei and $\bar{m}_{\mathrm{c}}(\mathrm{kg})$ and $n_{\mathrm{c}}\left(\mathrm{kg}^{-1}\right)$ are the averaged cloud-droplet mass (i.e., total cloud-droplet mass divided by total cloud-droplet number in a unit volume) and number mixing ratio of droplets, respectively. $\rho_{\mathrm{a}}$ is the air density. $D_{\text {ap }}$ is given by

$D_{\text {ap }}=\frac{k T C_{\mathrm{c}}}{6 \pi \eta r_{\mathrm{m}}}$

where $k$ is the Boltzmann constant, $T$ is the temperature, $\eta$ is the viscosity of air $\left\{\eta=10^{-5}\left(1.718+0.0049\left(T-T_{0}\right)-\right.\right.$ $\left.1.2 \times 10^{-5}\left(T-T_{0}\right)^{2}\right)$ in $\left.\mathrm{kg} \mathrm{m}^{-1} \mathrm{~s}^{-1}\right\}, r_{\mathrm{m}}$ is the aerosol mode radius, and $C_{\mathrm{c}}$ is the Cunningham correction factor $\left[C_{\mathrm{c}}=\right.$ $\left.1+1.26\left(\frac{\lambda}{r_{\mathrm{m}}}\right)\left(\frac{p_{0}}{p}\right)\left(\frac{T}{T_{0}}\right)\right]$. The aerosol mode radius is taken to be $0.2 \mu \mathrm{m}$ for dust and $0.1 \mu \mathrm{m}$ for BC. $\lambda$ is the mean free path length of air $\left(\lambda=0.066 \mu \mathrm{m}\right.$ at the surface), $p_{0}$ and $T_{0}$ refer to the standard pressure of $101325 \mathrm{~Pa}$ and the freezing temperature of $273.15 \mathrm{~K}$. $N_{\mathrm{a} \text {,cnt }}$ is obtained from the number concentration of aerosol particles consisting of $\mathrm{BC}$ and dust, multiplied by a temperature dependence for the individual species. This temperature dependence is based on Fig. 1 in Lohmann and Diehl (2006). Here, for dust, the temperature dependence of montmorillonite is adopted (Lohmann and Diehl, 2006). For immersion and condensation-freezing activation:

$\frac{d N_{\mathrm{IMM}}}{d t}\left(\mathrm{~m}^{-3} \mathrm{~s}^{-1}\right)=a N_{\mathrm{a}, \mathrm{imm}} \exp \left[a\left(T_{0}-T\right)\right] \frac{d T}{d t} \frac{\rho_{\mathrm{a}} q_{\mathrm{c}}}{\rho_{\mathrm{w}}}$

where $\frac{d N_{\mathrm{IMM}}}{d t}$ is the rate of the production of ice-crystal number concentration via immersion and condensation freezing, $a$ is $1.00 \mathrm{~K}^{-1}$, and $T_{0}$ the freezing temperature. $N_{\mathrm{a} \text {,imm }}\left(\mathrm{m}^{-3}\right)$ is the number concentration of immersion and condensation nuclei calculated as the number concentration of $\mathrm{BC}$

\section{Initial potential temperature and humidity}

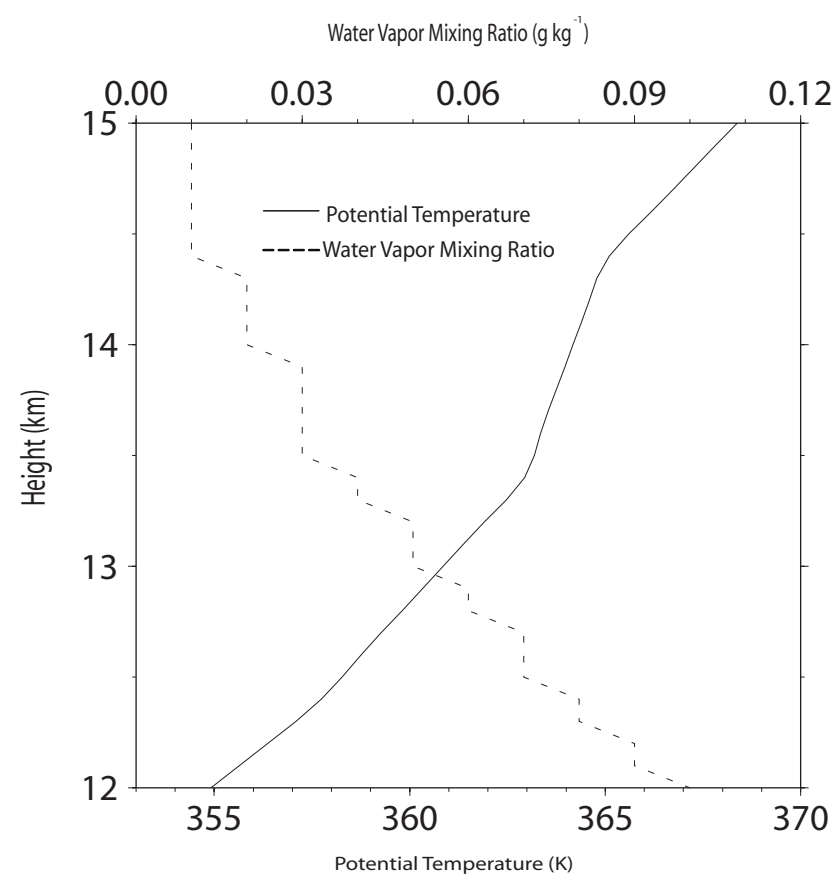

Fig. 1. Vertical profiles of initial potential temperature and water vapor mixing ratio.

and dust aerosols, multiplied by the temperature dependence for immersion and condensation freezing shown in Fig. 1 in Lohmann and Diehl (2006). As for contact freezing, the temperature dependence of montmorillonite is adopted for dust. For deposition nucleation, the parameterization of Möhler et al. (2006) is implemented. The rate of production of the icecrystal number concentration via deposition freezing is:

$\frac{d N_{\text {DEP }}}{d t}\left(\mathrm{~m}^{-3} \mathrm{~s}^{-1}\right)=\frac{N_{\mathrm{a}, \operatorname{dep}}\left(\exp \left[b\left(S_{\mathrm{i}}-S_{0}\right)\right]-1\right)}{\Delta t}$

where $b$ and $S_{0}$ are non-dimensional empirical constants determined by chamber experiments, which are dependent on aerosol properties. $\Delta t$ is the time step. Here $b$ and $S_{0}$ are set to 4.77 and 1.07 , respectively, based on experiments for desert dust. $N_{\mathrm{a}, \text { dep }}$ is the number concentration of deposition nuclei $\left(\mathrm{m}^{-3}\right)$ calculated from the predicted total dust mass concentration. Equation (4) is applied at temperatures colder than $-40{ }^{\circ} \mathrm{C}$ and restricted to $S_{0}<S_{\mathrm{i}}<1.63+6.52 \times 10^{-3} \times a\left(T-T_{0}\right)$, corresponding to the measured saturation region where pure deposition nucleation occurs (Field et al., 2006). The parameterization is limited to activating a maximum of $5 \%$ of the dust, following the measurements of Field et al. (2006). As indicated by the experiments of Field et al. (2006), Eq. (4) is only valid at temperatures below $-40^{\circ} \mathrm{C}$. At temperatures warmer than $-40^{\circ} \mathrm{C}$, the parameterizations of Meyer et al. (1992) and DeMott et al. (2003), multiplied by a scaling factor to consider 
the dependence of IN activation on dust mass concentration, are used. These parameterizations for temperatures both below and above $-40^{\circ} \mathrm{C}$ are only applied to grid points with no cloud liquid to ensure that only deposition nucleation is calculated. For temperatures warmer than $-40^{\circ} \mathrm{C}$, deposition freezing is limited to activating a maximum of $0.5 \%$ of the dust, since Field et al. (2006) found that deposition nucleation did not activate more than $0.5 \%$ of the dust at these temperatures. Details of these parameterizations can be found in Appendix A.

Homogeneous aerosol (haze particle) freezing is assumed to occur instantaneously when a size- and temperaturedependent critical supersaturation with respect to ice for the freezing is exceeded. It is represented by considering the predicted size distribution of unactivated aerosols. A lookup table for the critical supersaturation ratio at which $\mathrm{CCN}$ freezes homogeneously is based on the theory proposed by Koop et al. (2000).

\subsection{Crystal habit}

To account for the variability of crystal type under different environmental conditions, the capacitance and massdimensional relations of pristine ice crystals and snow are allowed to vary. Since the model does not keep track of the history of all crystals, a simple diagnostic check of the ambient temperature and saturation conditions at each grid location is performed during each time-step to determine the crystal habit; see Table 1 in Meyers et al. (1997) for the habit diagnosis adopted here. The habit diagnosis impacts the model in several ways. The capacitance is dependent on crystal type (Harrington et al., 1995) and may change the growth characteristics of the crystals. Different types of crystals fall at different speeds which is determined by the power law relation

$v_{\mathrm{t}}\left(\mathrm{m} \mathrm{s}^{-1}\right)=a_{\mathrm{vt}} D(\mathrm{~m})^{b_{\mathrm{vt}}}$

where $D$ is the crystal maximum dimension and $a_{\mathrm{vt}}$ and $b_{\mathrm{vt}}$ are constants for a given crystal habit (see Walko et al. (1995) for details of these constants).

\section{Case descriptions}

A case of cirrus clouds located at $\left(20^{\circ} \mathrm{N}, 30^{\circ} \mathrm{W}\right)$ off the coast of Western Africa is simulated here. A pair of simulations from 06:00 LST (local solar time) on 1 July to 18:00 LST on 1 July in 2002 are performed in which the aerosol concentration is varied from the preindustrial (PI) level to the presentday (PD) level. The simulation with the PD (PI) level is referred to as the high-aerosol (low-aerosol) run, henceforth. The PD and PI aerosol concentrations were diagnosed from a simulation with the CAM-IMPACT aerosol model (Wang et al., 2009; see below).
Reanalysis data from the European Centre for MediumRange Weather Forecasts (ECMWF) provide initial conditions and large-scale forcings. Following Krueger et al. (1996), interpolation of the 6-hourly analyses were used to determine the large-scale advective tendency of potential temperature and specific humidity at every time step. The temperature and humidity fields were nudged toward the large-scale fields from the ECMWF using a relaxation time of $1 \mathrm{~h}$. The horizontally averaged wind from the GCE model was also nudged toward the interpolated wind field from the ECMWF at every time step with a relaxation time of one hour, following $\mathrm{Xu}$ et al. (2002). The model domain is considered to be small compared to large-scale disturbances which have a spatial scale of $\sim 200-300 \mathrm{~km}$ or larger. Hence, the large-scale advection is approximated to be uniform over the model domain and large-scale terms are defined to be functions of height and time only, following Krueger et al. (1999). Identical observed surface fluxes of heat and moisture were prescribed in both the high- and lowaerosol runs. This method of modeling cloud systems was used for the CSRM comparison study by Xu et al. (2002). The details of the procedure for applying large-scale forcing are described in Donner et al. (1999) and are similar to the method proposed by Grabowski et al. (1996).

Vertical profiles of the initial specific humidity and potential temperature between 12 and $15 \mathrm{~km}$ are shown in Figure 1; the simulated cloud layer (which will be described later) is located between 12.5 and $14.5 \mathrm{~km}$. The vertical distribution of the time- and area-averaged large-scale forcings of potential temperature and specific humidity imposed between 12 and $15 \mathrm{~km}$ is depicted in Fig. 2. The initial humidity decreases with height nearly monotonically. The initial potential temperature increases with height with a less stable layer between 13.5 and $14.5 \mathrm{~km}$ than that above and below these levels as shown in Fig. 1. The large-scale potential-temperature forcing shows two peaks around 12.5 and $14.5 \mathrm{~km}$ and the large-scale humidity forcing increases up to around $12.5 \mathrm{~km}$ and then decreases to zero around $14 \mathrm{~km}$.

The simulations are performed in a 3-D framework. A uniform grid length of $100 \mathrm{~m}$ is used in the horizontal domain and the vertical grid length is uniformly $50 \mathrm{~m}$ above $10 \mathrm{~km}$.

Periodic boundary conditions are used on the horizontal boundaries to prevent boundary conditions from affecting net water and energy budget. This enables only large-scale forcings to affect the net budget and, thus, large-scale forcings (representing large-scale meteorology) only (but not boundary conditions) controls the water and energy flow into and out of domain. This mimics the effect of large-scale environment on clouds with no physical cloud-domain boundaries in reality.

The horizontal domain length is set to $12 \mathrm{~km}$ in both the east-west and north-south directions. The vertical domain length is $20 \mathrm{~km}$ to cover the troposphere and the lower stratosphere. 
Table 1. Domain-averaged budget terms of cloud ice.

\begin{tabular}{|c|c|c|c|c|c|c|c|c|c|}
\hline & $\begin{array}{l}\text { High- } \\
\text { aerosol }\end{array}$ & $\begin{array}{r}\text { High- } \\
\text { aerosol } \\
\text { (CINC- } \\
\text { high } \\
\text { fixed) }\end{array}$ & $\begin{array}{r}\text { High- } \\
\text { aerosol } \\
\text { (CINC- } \\
\text { low } \\
\text { fixed) }\end{array}$ & $\begin{array}{r}\text { Low- } \\
\text { aerosol }\end{array}$ & $\begin{array}{r}\text { Low- } \\
\text { aerosol } \\
\text { (CINC- } \\
\text { high } \\
\text { fixed) }\end{array}$ & $\begin{array}{r}\text { Low- } \\
\text { aerosol } \\
\text { (CINC- } \\
\text { low } \\
\text { fixed) }\end{array}$ & $\begin{array}{r}\text { High } \\
\text { minus } \\
\text { Low }\end{array}$ & $\begin{array}{r}\text { High } \\
\text { minus } \\
\text { Low } \\
\text { (CINC- } \\
\text { high fixed) }\end{array}$ & $\begin{array}{r}\text { High } \\
\text { minus } \\
\text { Low } \\
\text { (CINC- } \\
\text { low fixed) }\end{array}$ \\
\hline $\operatorname{IWP}\left(\mathrm{g} \mathrm{m}^{-2}\right)$ & 2.68 & 2.62 & 2.13 & 2.11 & 2.58 & 2.06 & 0.57 & 0.04 & 0.07 \\
\hline $\begin{array}{l}\left\langle Q_{\text {depo }}\right\rangle \\
\text { Deposition }(\mu \mathrm{m})\end{array}$ & 5.42 & 5.39 & 4.68 & 4.66 & 5.31 & 4.58 & 0.76 & 0.08 & 0.10 \\
\hline $\begin{array}{l}\left\langle Q_{\text {subl }}\right\rangle \\
\text { Sublimation }(\mu \mathrm{m})\end{array}$ & 1.06 & 1.02 & 0.48 & 0.46 & 1.01 & 0.44 & 0.60 & 0.01 & 0.04 \\
\hline $\begin{array}{l}\left\langle Q_{\text {auto }}\right\rangle \\
\text { Autoconversion of cloud } \\
\text { ice to aggregates } \\
+ \\
\left\langle Q_{\text {accr }}\right\rangle \\
\text { Accretion of cloud } \\
\text { ice by aggregates } \\
(\mu \mathrm{m})\end{array}$ & 0.021 & 0.020 & 0.015 & 0.023 & 0.028 & 0.022 & -0.002 & -0.008 & -0.007 \\
\hline $\begin{array}{l}\left\langle\left|Q_{\text {ased }}\right|\right\rangle \\
\text { Sedimentation of aggregates above } \\
\text { the cloud base }(\mu \mathrm{m})\end{array}$ & 0.050 & 0.050 & 0.047 & 0.051 & 0.053 & 0.050 & -0.001 & -0.003 & -0.003 \\
\hline $\begin{array}{l}\left\langle\left|Q_{\text {ised }}\right|\right\rangle \\
\text { Sedimentation of cloud ice above the } \\
\text { cloud base }(\mu \mathrm{m})\end{array}$ & 0.71 & 0.71 & 0.65 & 0.73 & 0.74 & 0.70 & -0.02 & -0.03 & -0.05 \\
\hline $\begin{array}{l}\left(\left\langle Q_{\text {auto }}\right\rangle+\left\langle Q_{\text {accr }}\right\rangle\right) /\left\langle Q_{\text {depo }}\right\rangle \\
\left|\Delta\left(\left\langle Q_{\text {auto }}\right\rangle+\left\langle Q_{\text {accr }}\right\rangle\right)\right| /\left|\Delta\left\langle Q_{\text {depo }}\right\rangle\right| \\
\text { for "High minus Low" }\end{array}$ & 0.004 & 0.004 & 0.003 & 0.005 & 0.005 & 0.005 & 0.003 & 0.100 & 0.070 \\
\hline $\begin{array}{l}<\left|Q_{\text {ased }}\right|>/\left\langle Q_{\text {depo }}\right\rangle \\
\left|\Delta\left\langle\left|Q_{\text {ased }}\right|\right\rangle\right| /\left|\Delta\left\langle Q_{\text {depo }}\right\rangle\right| \\
\text { for "High minus Low" }\end{array}$ & 0.009 & 0.009 & 0.010 & 0.011 & 0.010 & 0.011 & 0.001 & 0.038 & 0.030 \\
\hline $\begin{array}{l}\left\langle\left|Q_{\text {ised }}\right|\right\rangle /\left\langle Q_{\text {depo }}\right\rangle ; \\
\left|\Delta\left\langle\left|Q_{\text {ised }}\right|\right\rangle\right| /\left|\Delta\left\langle Q_{\text {depo }}\right\rangle\right| \\
\text { for "High minus Low" }\end{array}$ & 0.13 & 0.13 & 0.14 & 0.16 & 0.14 & 0.15 & 0.03 & 0.38 & 0.50 \\
\hline
\end{tabular}

Background aerosol data for the high-aerosol run and the low-aerosol run were provided by the CAM-UMICH model. Aerosol data produced at $\left(20^{\circ} \mathrm{N}, 30^{\circ} \mathrm{W}\right)$ from the PD and PI emissions were used for the high-aerosol run and lowaerosol run, respectively. The detailed description of the CAM-UMICH model and aerosol emissions can be found in Wang et al. (2009). The aerosol number concentration is calculated from the mass profiles using the parameters (mode radius, standard deviation, and partitioning among modes) described in Chuang et al. (1997) for sulfate aerosols and Liu et al. (2005) for non-sulfate aerosols (e.g., fossil fuel $\mathrm{BC} / \mathrm{OM}$, biomass BC/OM, sea salt, and dust). Here, a bi- modal log-normal size distribution is assumed for sulfate and sea salt aerosols. For fossil fuel BC/OM, biomass BC/OM, and dust, a tri-modal log-normal size distribution is assumed. $\mathrm{BC} / \mathrm{OM}$ aerosols are assumed to be internally mixed and act as $\mathrm{BC}$ aerosols for contact, immersion, and condensationfreezing activation of IN. Dust and BC/OM aerosols are assumed to act only as IN. Sulfate and sea salt aerosols are assumed to act only as $\mathrm{CCN}$ and thus as nuclei for haze particles; some of these haze particles go through homogeneous freezing. The number of aerosols in each size bin of the distribution is determined using the size parameters and an assumed aerosol particle density for each species. As for 
a

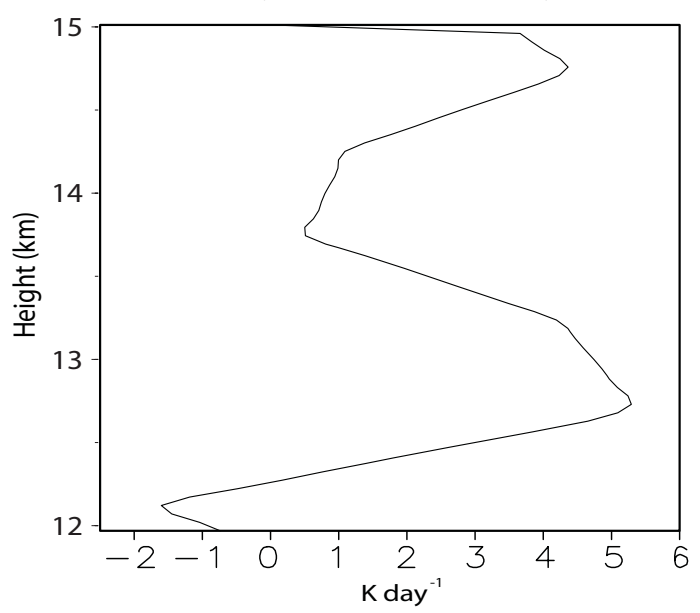

b

Large-scale humidity forcing

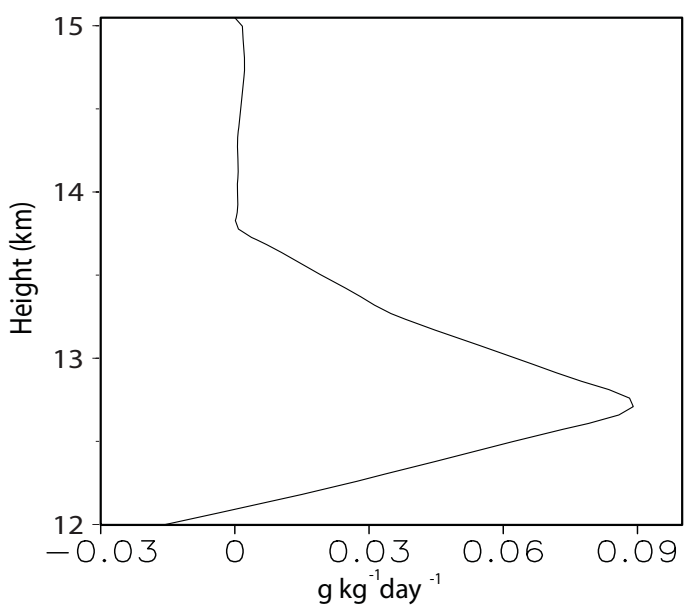

Fig. 2. Vertical distribution of the time- and area-averaged (a) potential temperature large-scale forcing and (b) humidity large-scale forcing.

the large-scale advection, the background aerosols are approximated to be uniform over the model domain and defined to be functions of height and time only. The timeand area-averaged vertical distribution of total background aerosol number between 12 and $15 \mathrm{~km}$ is shown in Fig. 3a. Generally, the aerosol number varies between 15 (10) and 30 (15) $\mathrm{cm}^{-3}$ for the high- (low-) aerosol run.

The aerosol is predicted within clouds and reset to the background value at all levels outside of cloud. Within clouds, aerosols are advected, diffused, and depleted by the nucleation of droplets and ice crystals (nucleation scavenging). Initially, the aerosol number is set equal to its background value everywhere. Hence, we focus on the examination of cloud responses to a given aerosol variation in the background aerosol amount between PI and PD conditions while considering the effect of cloud-scale processes on aerosols within clouds. a

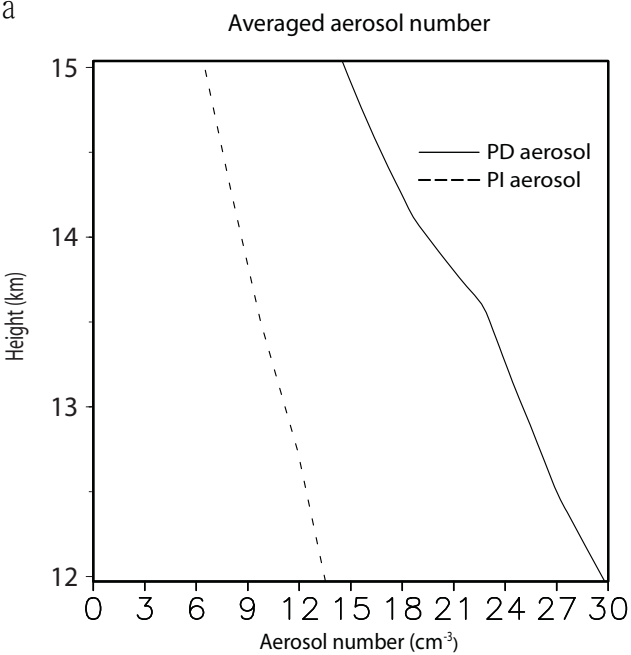

b

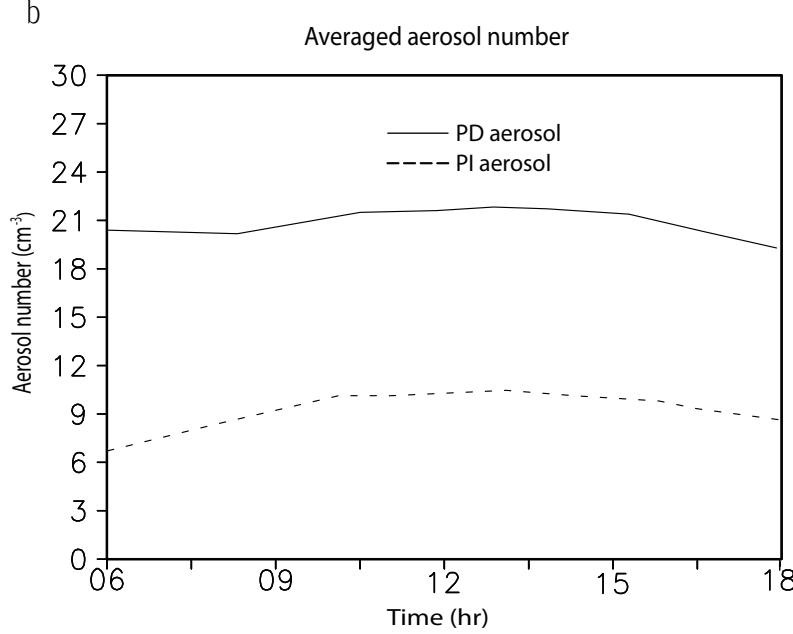

Fig. 3. (a) Vertical distribution of the time- and area-averaged background aerosol number concentration and (b) the time series of background aerosol number concentration averaged over the layer between 12 and $15 \mathrm{~km}$.

Figure $3 b$ shows the time series of the domain-averaged total background aerosol number over the layer between 12 and $15 \mathrm{~km}$. Figure $3 \mathrm{~b}$ indicates that aerosol number does not vary significantly over the simulation period. More than $\sim 90 \%$ of aerosol number in both the high-aerosol and low-aerosol runs are $\mathrm{CCN}$ (active as haze particles).

\section{Results}

\subsection{Cloud properties}

Clouds in the high- and low-aerosol runs are formed around 7 LST and they are mostly located between 12.5 and $14.5 \mathrm{~km}$ during the simulation period. 


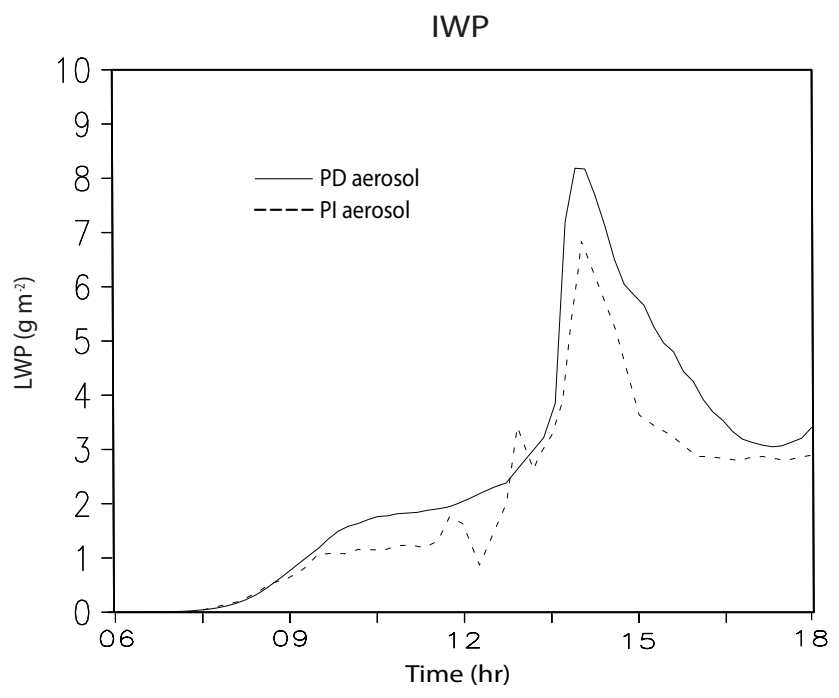

Fig. 4. Time series of the domain-averaged IWP.

Figure 4 shows the temporal evolution of domain-averaged IWP. Here, only cloud ice is included for the calculation of the IWP. Figure 4 shows that the IWP in the high-aerosol run is generally higher than that in the low-aerosol run by $\sim 1-$ $2 \mathrm{~g} \mathrm{~m}^{-2}$ during the time integration. The time- and domainaveraged IWP is $2.68(2.11) \mathrm{g} \mathrm{m}^{-2}$ for the high (low) aerosol case.

The simulated IWP in the high-aerosol run is compared to observations by the Moderate Resolution Imaging Spectroradiometer (MODIS) to assess the ability of the model to simulate cirrus clouds. The difference between the domainaveraged IWP in the high-aerosol run $\left(2.68 \mathrm{~g} \mathrm{~m}^{-2}\right)$ and MODIS-observed IWP $\left(2.86 \mathrm{~g} \mathrm{~m}^{-2}\right)$ is less than $10 \%$ relative to IWP observed by the MODIS;Since MODIS ice particles have sizes which range from 8 to $120 \mu \mathrm{m}$, and these sizes are included in the ice-crystal category in the model, MODIS also only includes ice crystals in its reported IWP. This demonstrates that the IWP is simulated reasonably well.

Also, the differences in the averaged IWP between the high- and low-aerosol runs are approximately 3 times larger than the differences between the MODIS value and the highaerosol-run mean. Tests with different water-vapor random perturbations at the first time step to trigger clouds show that these differences are statistically robust.

\subsection{Nucleation}

Figure 5 shows the vertical distribution of the homogeneous and heterogeneous in-cloud averaged nucleation rate for the high- and low-aerosol runs. The homogeneous freezing of haze particles dominates over that of heterogeneous nucleation for the production of CINC; the production of CINC through the homogeneous freezing of haze particles is $\sim$ one order of magnitude larger than that through the heterogeneous nucleation of ice particles. Kärcher and Ström (2003)

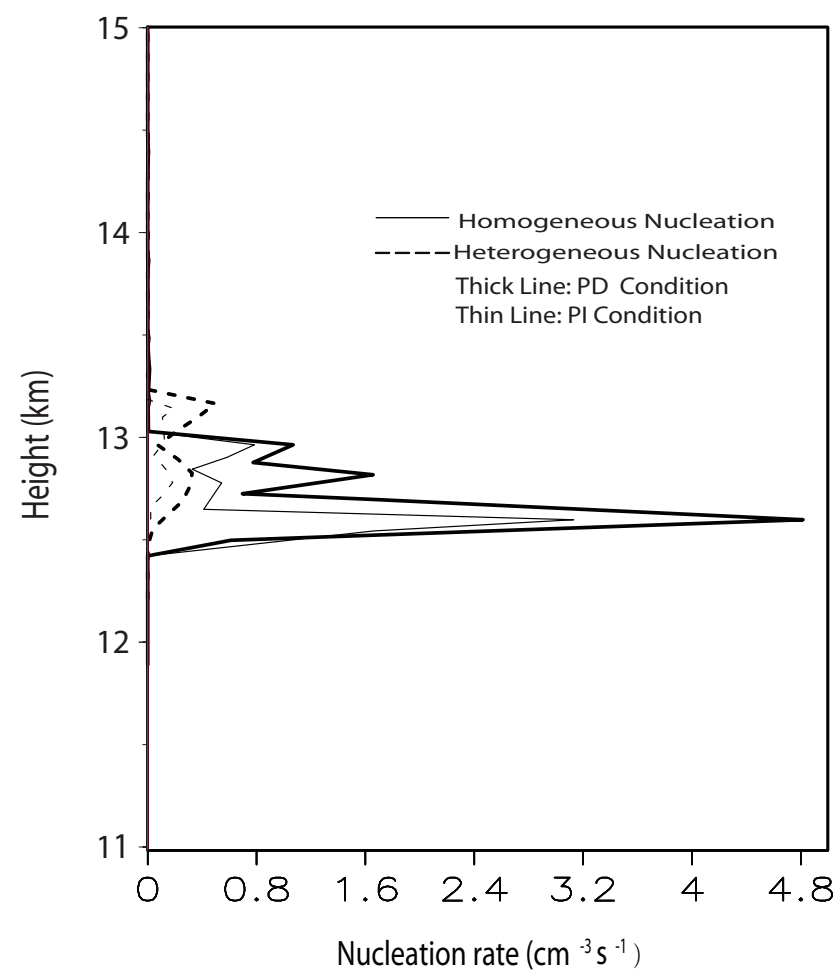

Fig. 5. Vertical distribution of the time- and area-averaged homogeneous and heterogeneous nucleation rates.

also reported the dominance of homogeneous freezing over heterogeneous nucleation based on an observation of midlatitude cirrus clouds. This dominance of homogeneous freezing indicates that relative humidity is much larger than that where heterogeneous nucleation starts to occur (Spichtinger and Gierens, 2009). Also, the difference in the homogeneous freezing between the high- and low-aerosol runs is $\sim$ one order of magnitude larger than that in the heterogeneous nucleation. Haze particles are unactivated droplets which formed on $\mathrm{CCN}$. Hence, the number of haze particles and thus their homogeneous freezing are associated with $\mathrm{CCN}$ but not with IN. In the parameterization for homogeneous freezing in this study, haze particles with critical supersaturation smaller than the parcel supersaturation are turned into frozen ice crystals as described in Sect. 2.3. Note that this is similar to droplet nucleation explained by Köhler curve. The parcel supersaturation is lower in the high-aerosol run than in the low-aerosol run (the lower parcel-supersaturation is described in Sect. 4.4). Thus, there must be more CCN particles and thus haze particles (with smaller critical supersaturation than the parcel supersaturation) in the bins that nucleate to ice in order to explain the larger rate of homogeneous nucleation in the high-aerosol run. This larger number of haze particles is due to larger background aerosol number in the high-aerosol run. 


\subsection{Ice-water budget}

To elucidate the microphysical processes leading to the increase in IWP with increasing aerosols, the domain-averaged cumulative source (i.e., deposition) and sinks of cloud ice and their differences between the high-aerosol and lowaerosol runs (high aerosol - low aerosol) are obtained. For this, the production equation for cloud ice is integrated over the domain and duration of the simulations. Integrations over the domain and duration of simulation are denoted by \langle\rangle :

$$
\langle A\rangle=\frac{1}{L x L y} \iiint \rho_{\mathrm{a}} A d x d y d z d t
$$

where $L x$ and $L y$ are the domain length $(12 \mathrm{~km})$, in east-west and north-south directions, respectively, $\rho_{\mathrm{a}}$ is the air density and A represents a mass mixing ratio in this study. The budget equation for cloud ice is as follows:

$$
\left\langle\frac{\partial q_{\mathrm{i}}}{\partial t}\right\rangle=\left\langle Q_{\text {depo }}\right\rangle-\left\langle Q_{\text {subl }}\right\rangle-\left\langle Q_{\text {auto }}\right\rangle-\left\langle Q_{\text {accr }}\right\rangle
$$

Here, $q_{\mathrm{i}}$ is cloud-ice mixing ratio. $Q_{\text {depo }}, Q_{\text {subl }}, Q_{\text {auto }}$, and $Q_{\text {accr }}$ refer to the rates of water vapor deposition, sublimation, autoconversion of cloud ice to aggregates, and accretion of cloud ice by aggregates, respectively. Since cloud ice does not reach the surface, the surface precipitation of cloud ice is not included in Eq. (7).

Table 1 shows the budget numbers for Eq. (7) for the high- and low-aerosol runs. The high- and low-aerosol runs (CINC-high fixed) and (CINC-low fixed) will be described in the following sections. The budget numbers show that deposition and sublimation of cloud ice are $\sim$ one to two orders of magnitude larger than autoconversion and accretion. This indicates that the conversion of cloud ice (produced by deposition) to aggregates is highly inefficient in the high- and low-aerosol runs.

Autoconversion and accretion are processes that control the growth of aggregates and sedimentation of aggregates and sedimentation is generally proportional to the size of aggregates. Hence, the small contribution of the rate of autoconversion and accretion to IWP implies that cloud-mass (i.e., sum of cloud ice and aggregates) changes due to sedimentation of aggregates are not as significant as those due to deposition and sublimation.

Much larger differences in deposition and sublimation as compared to those in autoconversion and accretion between the high- and low-aerosol runs are simulated here (Table 1). This implies that changes in deposition and sublimation due to aerosol increases play much more important roles in the cloud-mass response to aerosols than those in the sedimentation of aggregates.

Table 1 shows the domain-averaged cumulative cloudmass changes due to in-cloud sedimentation of aggregates for the high- and low-aerosol runs; here, the absolute value of the sedimentation-induced mass change is presented. In Table 1, the rates of sedimentation of aggregates and cloud ice are represented by $Q_{\text {ased }}$ and $Q_{\text {ised, }}$, respectively. The magnitude of deposition is $\sim$ one order of magnitude larger than that of cloud-mass changes induced by the sedimentation of aggregates (Table 1). Also, the magnitude of the difference in deposition between the high- and low-aerosol runs is $\sim$ two to three orders of magnitude larger than that for mass changes induced by the sedimentation of aggregates (Table 1). Hence, in general, as implied by the budget analysis, the role of the sedimentation of aggregates in the determination of the cloud mass and its response to aerosols is negligible as compared to that of deposition. The role of the sedimentation of cloud ice plays a much more important role in this determination and response than that of the sedimentation of aggregates as shown in Table 1. However, the role of deposition is still much more important than that of the sedimentation of cloud ice. The domain-averaged cumulative cloud-mass changes due to in-cloud sedimentation of cloud ice is $\sim 13$ and $16 \%$ of the domain-averaged cumulative deposition in the high-aerosol run and the low-aerosol run, respectively. Also, the difference in the sedimentation of cloud ice between the high- and low-aerosol runs is $~ 3 \%$ of that in deposition.

\subsection{Factors controlling deposition}

The mass changes of ice crystals from the diffusion of vapor, integrated over the size distribution, is as follows:

$\frac{d \bar{m}}{d t}=N_{\mathrm{i}} 2 \pi \psi F_{\mathrm{Re}} S \rho_{\mathrm{vsh}}$

where $N_{\mathrm{i}}$ is CINC, $\psi$ the vapor diffusivity, and $\rho_{\mathrm{vsh}}$ the saturation water vapor mixing ratio over ice. $S$ is the supersaturation, given by $\left(\frac{\rho_{\mathrm{va}}}{\rho_{\mathrm{vsh}}}-1\right)$ where $\rho_{\mathrm{va}}$ is water vapor mixing ratio. $F_{\mathrm{Re}}$ is the integrated product of the ventilation coefficient, the crystal shape factor and the maximum dimension which is given by

$$
F_{\mathrm{Re}}=\int_{0}^{\infty} C f_{\mathrm{Re}} f_{\mathrm{gam}}(D) d D
$$

where $D$ is the crystal maximum dimension, $C$ the crystal capacitance, $f_{\mathrm{Re}}$ the ventilation coefficient, and $f_{\mathrm{gam}}(D)$ the gamma distribution function, given by Eq. (1). $f_{\mathrm{Re}}$ is given by $\left[1.0+0.229\left(\frac{v_{\mathrm{t}} D}{V_{\mathrm{k}}}\right)^{0.5}\right] \eta$ where $v_{\mathrm{t}}$ is the terminal velocity and $V_{\mathrm{k}}$ the kinematic viscosity of air and $\eta$ the shape parameter (Cotton et al., 1982).

Among the variables associated with the depositional growth of cloud ice in Eq. (8), differences in the supersaturation and CINC contribute most to the differences in deposition between the high- and low-aerosol runs. Percentage differences in the other variables are found to be $\sim$ two orders of magnitude smaller than those in supersaturation and CINC throughout the simulations. Figure 6a shows the time series of CINC and Fig. $6 \mathrm{~b}$ the time series of supersaturation. 


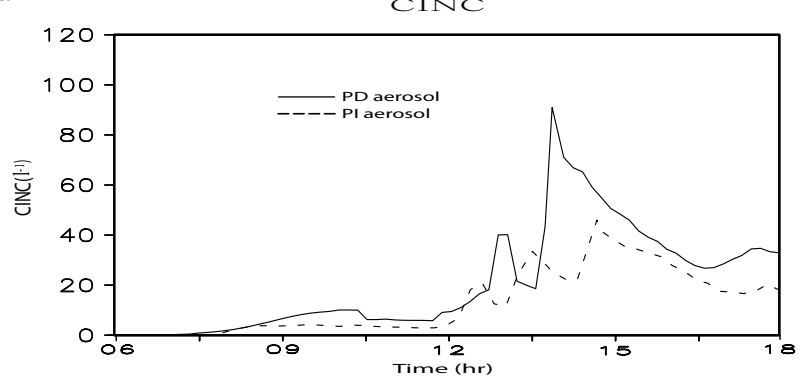

b
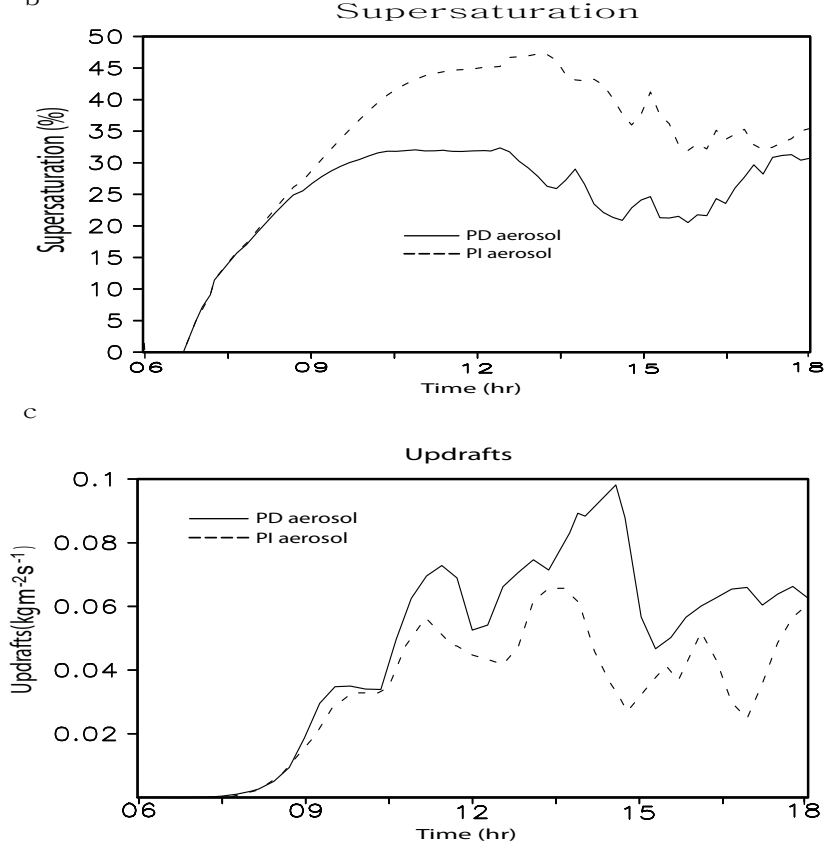

Fig. 6. Time series of conditionally averaged (a) CINC and (b) supersaturation over areas where deposition rate is positive and (c) the time series of the domain-averaged updrafts.

Figure $6 \mathrm{~b}$ indicates that supersaturation is generally larger at low aerosol than at high aerosol. However, the deposition rate is generally higher, leading to larger cumulative deposition at high aerosol than at low aerosol (Table 1). This is ascribed to the larger CINC (as shown in Fig. 6a) providing a larger surface area for water-vapor deposition at high aerosol compared to that at low aerosol. The effects of the CINC increase on the surface area of cloud ice and thus deposition compete with the effects of the supersaturation decrease on the deposition with increasing aerosols. This leads to a smaller deposition difference than the differences in CINC and supersaturation. The effects of the increased surface area for deposition outweigh the effects of decreased supersaturation, leading to the increase in vapor deposition in the high aerosol run.

Increased deposition provides more depositional heating, and, thereby, intensifies updrafts as shown in Fig. 6c which depicts the time series of domain-averaged updraft mass fluxes. Increased updrafts in turn increase deposition, establishing a positive feedback between updrafts and deposition. Therefore, the ice crystal number concentration provides a larger surface area for deposition and plays a critical role in increasing both deposition and updrafts. The interactions among CINC, deposition and dynamics (i.e., updrafts) play the most important role in the determination of the differences in deposition and thereby the IWP response to aerosols between the high- and low-aerosol runs.

\subsection{Runs with different CINC for water vapor deposition}

To isolate the role of the impacts of CINC (i.e., the surface area of ice crystals) on deposition in making IWP differences, the high- and low-aerosol runs are repeated with identical CINC only for deposition but not for the other processes including sublimation. This isolates the processes that determine the IWP differences in the absence of the impacts of the surface area of ice crystals on deposition. The comparison of these simulations to simulations described in previous sections (i.e., the high- and low-aerosol runs) enables an assessment of the contribution of aerosol and thus CINC impacts on deposition to the IWP differences.

Two pairs of additional simulations, each of which is composed of the high- and low-aerosol runs, are performed. Each pair of simulations adopts the identical CINC only for deposition; $N_{\mathrm{i}}$ in Eq. (8) is fixed at a constant value and forced to be the same for the high- and low-aerosol runs, though the predicted $N_{\mathrm{i}}$ is allowed to be used in the other processes. The first pair of simulations is referred to as the high-aerosol run (CINC-high fixed) and low-aerosol run (CINC-high fixed) in Table 1. These CINC-high fixed runs adopt the averaged CINC in the high-aerosol run, which is $381^{-1}$, as a fixed value only for deposition. The second pair of simulations adopt the averaged CINC in the low-aerosol run, which is $211^{-1}$, as a fixed value only for deposition and are referred to as the high-aerosol run (CINC-low fixed) and the low-aerosol run (CINC-low fixed) in Table 1.

The budget numbers for Eq. (7) for these additional simulations are shown in Table 1. The time- and domain-averaged IWPs in the high-aerosol run (CINC-high fixed) and lowaerosol run (CINC-high fixed) are 2.62 and $2.58 \mathrm{~g} \mathrm{~m}^{-2}$. The IWP in the low-aerosol run (CINC-high fixed) increases significantly as compared to the IWP in the low-aerosol run, resulting in much smaller differences in IWP between the high- and low-aerosol runs (CINC-high fixed) than those between the original high- and low-aerosol runs. This is mainly due to larger CINC in the low-aerosol run (CINC-high fixed) than the average CINC in the low-aerosol run, leading to increased deposition as compared to that in the low-aerosol run (Table 1).

The IWP differences between the high-aerosol run with CINC-low fixed and low-aerosol run with CINC-low fixedare also much smaller as compared to those in the original 
high- and low-aerosol runs (Table 1). IWPs in the highaerosol run with CINC-low fixed and low-aerosol run with CINC-low fixed are 2.13 and $2.06 \mathrm{~g} \mathrm{~m}^{-2}$, respectively. IWP in the high-aerosol run with CINC-low fixed decreases significantly as compared to that in the original high-aerosol run, resulting in the small differences in IWP between the high-aerosol run with CINC-low fixed and low-aerosol run with CINC-low fixed (Table 1). This is mainly due to smaller CINC in the high-aerosol run with CINC-low fixed than the average CINC in the original high-aerosol run, leading to less deposition than in the high-aerosol run (Table 1).

These additional simulations indicate that the IWP responses to aerosols can be nearly the same for the high- and low-aerosol runs only by making the CINC for deposition identical. This demonstrates the crucial role of CINC impacts on deposition in the IWP response to aerosols. This also demonstrates that the impacts of aerosols and thus CINC on the other processes such as the sedimentation of ice crystals and aggregates and the conversion of ice crystals to aggregates do not play an important role in the IWP response to aerosols.

\subsection{Test simulations with different types of aerosols for nucleation}

The homogeneous freezing of haze particles formed on $\mathrm{CCN}$ dominates the CINC and its response to aerosols as described in Sect. 4.2. This indicates that the CINC and its response to aerosols are controlled by CCN but not by IN. To confirm this, simulations are repeated with no variation of aerosols acting as CCN (fixed at the PI level) but with the variation of aerosols (from their PI level to PD level) acting as IN between the high- and low-aerosol runs. These simulations show $\sim 2 \%$ of the variation in deposition and $\sim 5 \%$ of the variation in IWP as compared to those in the standard highand low-aerosol runs. However, another set of repeated simulations only with $\mathrm{CCN}$ variation (with no variation of IN, which was fixed at the PI level) shows $98 \%$ of the variation in deposition and $94 \%$ of the variation in IWP as compared to those in the standard high- and low-aerosol runs. Hence, these repeated simulations demonstrate that the results here are determined mainly by the variation of $\mathrm{CCN}$ between the $\mathrm{PD}$ and PI conditions and that their dependence on IN variation is negligible.

\subsection{Radiation budget}

Upward shortwave (SW) and longwave fluxes (LW) at the top of the atmosphere (TOA) are presented in Table 2.

The low-aerosol run has a smaller TOA upward SW flux (here, TOA is at the level of $0.01 \mathrm{hPa}$ ) than the high-aerosol run; more SW is reflected in the high-aerosol run than in the low-aerosol run by $15.4 \mathrm{~W} \mathrm{~m}^{-2}$. The averaged effective size (optical depth) over cloudy areas is $30 \mu \mathrm{m}(0.43)$ and $33 \mu \mathrm{m}$ (0.29) for the high- and low-aerosol runs, respectively. The
Table 2. Time- and area-averaged upward shortwave flux (SW) and longwave flux (LW) at the top of the atmosphere (TOA).

\begin{tabular}{lrr}
\hline \multicolumn{3}{c}{ TOA } \\
\hline & \multicolumn{2}{c}{ CONTROL } \\
& SW & LW \\
\hline Low aerosol & 231.1 & 497.7 \\
High aerosol & 246.5 & 492.2 \\
Difference (high - low) & 15.4 & -5.5 \\
\hline
\end{tabular}

percentage difference in the effective size between the high and low-aerosol runs is $\sim 3$ times smaller than that in IWP. Hence, the difference in IWP accounts for most of the difference in the optical depth rather than the change in effective size. Therefore, most of the radiation difference between the high- and low-aerosol runs is associated with the IWP variation.

More longwave radiation emitted from the surface is absorbed by clouds in the high-aerosol run than in the lowaerosol run due to its higher IWP. Hence, the longwave reaching the top of the atmosphere (i.e., the outgoing longwave radiation) is smaller in the high-aerosol run than in the low-aerosol run (Table 2). These changes in longwave radiation partially offset the changes in shortwave radiation. The increase of the reflected solar radiation due to aerosol increases is offset by the decrease of the outgoing longwave radiation by $35 \%$. This offset is much larger than the offset in stratocumulus clouds. For example, Lee et al. (2009) showed that, for the transition from the maritime aerosols to continental aerosols which involves a 10-fold increase in aerosol number, only less than $3 \%$ of increase in the reflection of solar radiation is offset by the decrease in the outgoing longwave radiation in stratocumulus clouds.

\section{Summary and conclusion}

Aerosol-cloud interactions in cirrus clouds developing in an environment with large-scale low vertical motion off the coast of Western Africa in the summer in 2002 were simulated using a CSRM coupled with a double-moment microphysics. Present-day and preindustrial aerosols were prescribed to examine aerosol effects on IWP.

Simulations showed that increasing aerosols increased IWP. The conversion of ice crystals to aggregates through autoconversion and accretion played a negligible role in the IWP response to aerosols, as did the sedimentation of aggregates. Instead, it was found that feedbacks among CINC, deposition and dynamics played the most important role in the increased IWP at high aerosol; the increased CINC offsets the decreased supersaturation causing an increase in the vapor deposition with the increased aerosols. The role of the 
sedimentation of ice crystals plays a much more important role in the IWP response to aerosols than that of the sedimentation of aggregates. However, the cloud-mass change due to the aerosol-induced variation in sedimentation of ice crystals is $\sim$ one to two orders of magnitude smaller than that due to the aerosol-induced variation in feedbacks among CINC, deposition and dynamics. The IWP simulated here is $\sim$ one order of magnitude smaller than that in Lee et al. (2009) who simulated cirrus clouds coupled with deep convective motions. Hence, clouds here can be considered thin (as compared to cirrus clouds driven by deep convective motions) and, thus, the growth of ice crystals by depositional here is likely to be less efficient than that in clouds formed with deep convection. This contributes to the negligible role of the conversion of ice crystals to aggregates and sedimentation of hydrometeors in the IWP response to aerosols. This is because depositional growth and collisions among particles both play a critical role in the particle growth to a critical size for autoconversion.

The homogeneous freezing of haze particles was the dominant form of freezing for the determination of the CINC and its variation with the aerosol concentration. Heterogeneous nucleation processes played a negligible role in the determination of CINC. However, we note that the heterogeneous nucleation can be more important in cirrus clouds located lower altitudes than those simulated here, since homogeneous freezing is less efficient when background temperatures are warmer.

The traditional understanding of aerosol-cloud interactions proposed by Albrecht (1989) is based on the observation of warm stratocumulus clouds. It indicates that the response of the liquid-water path (LWP) to aerosol changes is controlled by the conversion of cloud liquid to rain and the sedimentation of rain. Cloud ice (or ice crystals) and aggregates in ice clouds above the level of homogeneous freezing (where liquid hydrometeors are absent) is equivalent to cloud liquid (or cloud droplets) and rain, respectively, in warm clouds. This is because cloud ice and cloud liquid both are considered to form from nucleation while rain and aggregates both are considered to form from autoconversion. Adopting this equivalence, it can be said that the traditional understanding of aerosol-cloud interactions is not applicable to the ice clouds simulated here due to the negligible role of the conversion of ice crystals to aggregates and the sedimentation of aggregates in the effect of aerosols on IWP. However, it should be pointed out that the conversion of ice crystals to aggregates can be more efficient in less cold cirrus clouds (located at lower altitudes) than the clouds simulated here. Thus, it is possible that the conversion of ice crystals to aggregates plays a more important role in the response of cloud mass to aerosols in clouds that are warmer than those simulated here. The varying role of the conversion of ice crystals to aggregates with varying cloud temperature or cloud altitude merits future studies.
The growth of ice crystals to precipitable hydrometeors through autoconversion and accretion is more efficient when liquid-phase particles are rimed onto these crystals than when only ice particles are involved in autoconversion and accretion. This is because the collection efficiencies are higher for collisions between liquid- and solid-phase particles than those between solid-phase particles. This contributes to the very low conversion efficiency (i.e., the ratio between the conversion of cloud ice to aggregates and deposition) and sedimentation, leading to a less important role for this conversion and sedimentation in the response of cloud mass to aerosols than that of deposition in this study.

The effect of changes in longwave radiation on ice clouds caused by increasing aerosols simulated here was only $\sim 35 \%$ of the increased outgoing shortwave radiation, though the global impact of this effect will depend on the relationship between the distribution of aerosols and synoptic motions in the upper troposphere, a matter which this study was not able to consider. However, it should be pointed out that as the optical depth of clouds increase, the increase in outgoing shortwave radiation can be enhanced and, thus, the offset of the increase in outgoing shortwave radiation by the decrease in outgoing longwave radiation can diminish. Hence, in clouds with a higher optical depth than the clouds simulated here, the offset by the decreased outgoing longwave radiation with the increased aerosols is likely to be smaller than simulated here. Also, we want to point out that cirrus clouds tend to be grey bodies (i.e. not black). Thus, the microphysical changes affect both longwave-radiation and shortwaveradiation cloud forcings in comparable ways, with aerosolinduced LW changes canceling those in SW more than reported here (only 35\%). This indicates that the compensation of aerosol-induced SW changes by those in LW can vary among cirrus clouds. The impact of this variation on global radiation budget and climate merits future study.

The coarse spatial resolutions employed in climate models are not able to resolve the interactions among CINC, deposition, and updrafts in the cloud layer, which play important roles in aerosol effects on IWP in cirrus clouds here. Parameterizations for the representation of the IWP variation with aerosols simply relying on changes in autoconversion and sedimentation with varying aerosols with no consideration of feedbacks between microphysics and dynamics in climate models can be misleading. This can contribute to a large uncertainty in the estimation of the radiative impact associated with aerosol indirect effects, considering the significant coverage of cirrus clouds. Also, most of climate models and some of CSRMs have adopted saturation adjustment schemes which are not able to predict supersaturation and to thereby consider the effects of changes in the surface area of cloud particles for the calculation of deposition. Hence, using a saturation adjustment scheme prevents the simulation of the changing competition between supersaturation and the surface area of cloud particles with increasing aerosols. This prevents the simulation of varying 
interactions among CINC, deposition, and dynamics with aerosols, which can lead to incorrect assessments of aerosol effects on cirrus clouds. Also, it is notable that while the change in longwave radiation is smaller than the change in shortwave radiation for the simulations shown here, the change in longwave radiation dominates that of shortwave radiation for the cirrus clouds perturbed by aerosol concentrations shown in Penner et al. (2009). Penner et al. (2009) examined an instantaneous response of cloud radiative forcing to cloud-particle number changes induced by aerosols. Our simulations show that aerosol-induced cloud-mass changes (through dynamic feedbacks) can affect whether changes in longwave radiation dominate those for shortwave radiation. Here, the consideration of changes in the IWP that result from feedbacks among CINC, deposition, and updrafts has actually decreased the LW impact relative to the SW impact as opposed to the simulations by Penner et al. (2009). This indicates that the effect of aerosols on the radiative properties of cirrus clouds and, hence, the assessment of aerosol indirect effects is highly sensitive to how sub-grid cloud-scale processes are represented in climate models. This also indicates that microphysics parameterizations (to represent subgrid cloud processes), able to predict particle mass and number, and thereby, surface area, coupled with a prediction of supersaturation, need to be implemented into climate models for a better assessment of aerosol effects on cirrus clouds.

The dependence of crystal optical properties on the crystal habit is a function of the aspect ratio of ice particles (Fu, 2007); the difference in the crystal optical properties is proportional to that in the aspect ratio characterizing the crystal habit. This study assumed the columnar shape of ice crystals for the characterization of the optical properties and thus calculation of radiative fluxes, following Phillips et al. (2007). The columnar shape has an aspect ratio of $\sim 0.3-0.5$, which corresponds to the lower range of aspect ratios of ice particles. Fu (2007) showed the increase in reflected SW by cirrus clouds by $\sim 2 \%$ when the crystal habit changes from a columnar shape to that for plates or dendrites having aspect ratios around 0.7-1.0 (corresponding to the upper range of the aspect ratio). Wendisch et al. (2007) showed that that change in the habit leads to $\sim 1.4-2.0 \%$ increases in outgoing LW. These changes in SW and LW would therefore cause less than a 5\% change to the offset of the reflected SW change by varying outgoing LW between the high- and low-aerosol runs shown in Table 2. This demonstrates that the qualitative nature of results of this study does not depend on crystal optical properties varying with the crystal habit.

The large-scale stability of cloud layer may have an impact on results here. To examine the effect of the stability on results here, the high- and low-aerosol runs were repeated with a varying stability. The first (second) set of these repeated high- and low-aerosol runs is with increased (decreased) potential-temperature gradient by a factor of 2 in cloud layer. With increased (decreased) stability, increases in deposition and IWP in this repeated high-aerosol run are smaller (larger) than the standard high-aerosol run. However, the more important role played by the rate of water vapor deposition in the IWP response to aerosols compared to that of the conversion of cloud ice to aggregates and the sedimentation of hydrometeors is also simulated in these repeated simulations. This demonstrates that the qualitative nature of the results presented here does not depend on the stability of cloud layer.

The generalization of the results reported here requires further investigation. The set of simulations examined here are too limited to form a generalized basis for determining the effects of aerosol on cirrus clouds and, thus, their parameterizations for large-scale or climate models. More case studies of cirrus clouds developing under various environmental conditions are needed to establish the generalization of the results reported here.

\section{Appendix A}

\section{Deposition nucleation at temperatures warmer than $-40^{\circ} \mathrm{C}$}

At temperatures between -30 and $-40{ }^{\circ} \mathrm{C}$ and between -5 and $-30^{\circ} \mathrm{C}$, DeMott et al. (2003) and Meyers et al.'s (1992) parameterizations, multiplied by a scaling factor, are used for deposition nucleation, respectively. For temperatures between -30 and $-40^{\circ} \mathrm{C}$ :

$$
N_{\text {IN }}\left(\mathrm{m}^{-3}\right)=1000\left(\exp \left[12.96\left(S_{\mathrm{i}}-1.1\right)\right]\right)^{0.3} \times \Psi
$$

Here, $N_{\text {IN }}$ is ice-crystal number concentration, $S_{\mathrm{i}}$ the saturation ratio with respect to ice and $\Psi$ a scaling factor to take into account the dependence of IN activation on dust mass. $\Psi$ is $\frac{\mathrm{DU}_{2.5}}{\mathrm{DU}_{2.5}^{*}}$, where $\mathrm{DU}_{2.5}$ is mass concentration of dust particles with diameter less than $2.5 \mu \mathrm{m}$ and $\mathrm{DU}_{2.5}^{*}$ is a reference dust mass concentration. $\mathrm{DU}_{2.5}^{*}$ is set to $0.11 \mu \mathrm{g} \mathrm{m}^{-3}$ based on dust data from the Mount Werner project used to derive Eq. (A1) (DeMott et al., 2003). Hence, Eq. (A1) computes $N_{\text {IN }}$ based on variation of dust mass relative to dust mass observed at the Mount Werner project. It was observed that IN concentrations were almost linear with the concentrations of large aerosol particles (Berezinskiy et al., 1986; Georgii and Kleinjung, 1967), supporting the assumption that $N_{\mathrm{IN}}$ is proportional to $\mathrm{DU}_{2.5}$. For temperatures between -5 and $-30^{\circ} \mathrm{C}$, the same scaling factor as used in Eq. (A1) is applied to the parameterization of Meyers et al. (1992) as follows, since dust mass data are not available in Meyers et al. (1992):

$N_{\text {IN }}\left(\mathrm{m}^{-3}\right)=63 \exp \left[12.96\left(S_{\mathrm{i}}-1\right)-0.639\right] \times \Psi$

Acknowledgements. The authors wish to thank Derek Posselt for providing the GCE coupled with the double-moment microphysics used here and for valuable discussions. This work was funded by the US Department of Energy ARM program (DE FG02 97 ER62370).

Edited by: P. Spichtinger 


\section{References}

Auer, A. H. and Veal, D. L.: The dimension of ice crystals in natural clouds, J. Atmos. Sci., 27, 919-926, 1970.

Albrecht, B. A.: Aerosols, cloud microphysics, and fractional cloudiness, Science, 245, 1227-1230, 1989.

Berezinskiy, N. A., Stepanov, G. V., and Khorguani, V. G.: Altitude variation of relative ice-forming activity of natural aerosol, $\mathrm{S}$. Meterol. Hydr., 12, 86-89, 1986.

Chou, M.-D. and Suarez, M. J.: A shortwave radiation parameterization for atmospheric studies, 15, NASA/TM-104606, 40 pp., 1999.

Chou, M.-D., Ridgway, W., and Yan, M.-H.: Parameterizations for water vapor IR radiative transfer in both the middle and lower atmospheres, J. Atmos. Sci., 52, 1159-1167, 1999.

Chuang, C. C., Penner, J. E., Taylor, K. E., Grossman, A. S., and Walton, J. J.: An assessment of the radiative effects of anthropogenic sulfate, J. Geophys. Res., 102, 3761-3778, 1997.

Cotton, W. R., Stephens, M. A., Nehrkorn, T., and Tripoli, G. J.: The Colorado State University three-dimensional cloud/mesoscale model. Part II: An ice phase parameterization, J. Rech. Atmos., 16, 295-319, 1982.

DeMott, P. J., Cziczo, D. J., Prenni, A. J., Murphy, D. M., Kreidenweis, S. M., Thomson, D. S., Borys, R., and Rogers, D. C.: Measurements of the concentration and composition of nuclei for cirrus formation, P. Natl. Acad. Sci. USA, 100(25), 1465514660, 2003.

Donner, L. J., Seman, C. J., and Hemler, R. S., Three-dimensional cloud-system modeling of GATE convection, J. Atmos. Sci., 56, 1885-1912, 1999.

Feingold, G., Tzivion, S., and Levin, Z.: Evolution of raindrop spectra. Part I: Solution to the stochastic collection/breakup equation using the method of moments, J. Atmos. Sci., 45, 3387-3399, 1988.

Feingold, G., Cotton, W., Kreidenweis, S., and Davis, J.: The impact of giant cloud condensation nuclei on drizzle formation in stratocumulus: Implications for cloud radiative properties, J. Atmos. Sci., 56, 4100-4117, 1999.

Field, P. R., Möhler, O., Connolly, P., Krämer, M., Cotton, R., Heymsfield, A. J., Saathoff, H., and Schnaiter, M.: Some ice nucleation characteristics of Asian and Saharan desert dust, Atmos. Chem. Phys., 6, 2991-3006, doi:10.5194/acp-6-2991-2006, 2006.

$\mathrm{Fu}, \mathrm{Q} .:$ A new parameterization of an asymmetry factor of cirrus clouds for climate models, J. Atmos. Sci., 64, 4144-4154, 2007.

$\mathrm{Fu}, \mathrm{Q}$.: An accurate parameterization of the solar radiative properties of cirrus clouds for climate models, J. Clim., 9, 2058-2082, 1996.

$\mathrm{Fu}, \mathrm{Q}$. and Liou, K. N.: Parameterization of the radiative properties of cirrus clouds, J. Atmos. Sci., 50, 2008-2025, 1993.

Grabowski, W. W., Wu, X., and Moncrieff, M. W.: Cloud resolving modeling of tropical cloud systems during phase III of GATE. Part I: Two-Dimensional Experiments, J. Atmos. Sci., 53, 36843709, 1996.

Georgii, H. W. and Kleinjung, E.: Relations between the chemical composition of atmospheric aerosol particles and the concentration of natural ice nuclei, J. Rech. Atmos., 3, 145-146, 1967.

Harrington, J. Y., Michael, P. M., Walko, R. L., and Cotton, R. C.: Parameterization of ice crystal conversion processes due to vapor deposition for mesoscale models using double-moment basis functions. Part I: Basic formulation and parcel model results, J. Atmos. Sci., 52, 4344-4366, 1995.

Houze, R. A.: Cloud dynamics, Academic Press, 573 pp., 1993.

Kärcher, B. and Ström, J.: The roles of dynamical variability and aerosols in cirrus cloud formation, Atmos. Chem. Phys., 3, 823838, doi:10.5194/acp-3-823-2003, 2003.

Klemp, J. B. and Wilhelmson, R.: The simulation of threedimensional convective storm dynamics, J. Atmos. Sci., 35, 1070-1096, 1978.

Koop, T., Luo, B. P., Tsias, A., and Peter, T.: Water activity as the determinant for homogeneous ice nucleation in aqueous solutions, Nature, 406, 611-614, 2000.

Kratz, D. P., Chou, M.-D., Yan, M.-H., and Ho, C.-H.: Minor trace gas radiative forcing calculations using the k-distribution method with one-parameter scaling, J. Geophy. Res., 103, 31647-31656, 1998.

Krueger, S. K., Cederwall, R. T., Xie, S. C., and Yio, J. J.: GCSS Working Group 4 Model Intercomparison-procedures for Case 3: Summer 1997 ARM SCM IOP, Draft manuscript obtainable from http://www.arm.gov/docs/scm/scmic3, 1999.

Lee, S. S., Donner, L. J., and Phillips, V. T. J.: Sensitivity of aerosol and cloud effects on radiation to cloud types: comparison between deep convective clouds and warm stratiform clouds over one-day period, Atmos. Chem. Phys., 9, 2555-2575, doi:10.5194/acp-9-2555-2009, 2009.

Liou, K. N.: Cirrus clouds and climate in McGraw-Hill Yearbook of Science and Technology, 432 pp., 2005.

Liou, K. N.: Influence of cirrus clouds on weather and climate processes: A global perspective, Mon. Weather Rev., 114, 11671199, 1986.

Liu, X., Penner, J. E., and Herzog, M.: Global modeling of aerosol dynamics: Model description, evaluation, and interactions between sulfate and nonsulfate aerosols, J. Geophys. Res., 110, D18206, doi:10.1029/2004JD005674, 2005.

Lohmann, U. and Diehl, K.:Sensitivity studies of the importance of dust ice nuclei for the indirect aerosol effect on stratiform mixedphase clouds, J. Atmos. Sci., 63, 968-982, 2006.

McFarquhar, G. M. and Black, R. A.: Observations of particle size and phase in tropical cyclones: Implications for mesoscale modeling of microphysical processes, J. Atmos. Sci., 61, 422-439, 2004.

Meyers, M. P., DeMott, P. J., and Cotton, W. R.: New primary icenulceation parameterization in an explicit cloud model, J. Appl. Meteor., 31, 708-720,1992.

Meyers, M. P., Walko, R. L., Harrington, J. Y., and Cotton, W. R.: New RAMS cloud microphysics parameterization. Part II: The two-moment scheme, Atmos. Res., 45, 3-39, 1997.

Möhler, O., Field, P. R., Connolly, P., Benz, S., Saathoff, H., Schnaiter, M., Wagner, R., Cotton, R., Krämer, M., Mangold, A., and Heymsfield, A. J.: Efficiency of the deposition mode ice nucleation on mineral dust particles, Atmos. Chem. Phys., 6, 3007-3021, doi:10.5194/acp-6-3007-2006, 2006.

Ono, A.: The shape and riming properties of ice crystals in natural clouds, J. Atmos. Sci., 26, 138-147, 1969.

Penner, J. E., Chen, Y., Wang, M., and Liu, X.: Possible influence of anthropogenic aerosols on cirrus clouds and anthropogenic forcing, Atmos. Chem. Phys., 9, 879-896, doi:10.5194/acp-9-8792009, 2009.

Penner, J. E., Andreae, M., Annegarn, H., et al.: Report to intergov- 
ernmental panel on climate change from the scientific assessment working group (WGI), in: Climate change 2001: The scientific basis, chap. 5, edited by: Houghton, J. T., Ding, Y., Griggs, D. J., et al., 289-348, Cambridge Univ. Press, New York, 2001.

Saleeby, S. M. and Cotton, W. R.: A large-droplet mode and prognostic number concentration of cloud droplets in the Colorado state university regional atmospheric modeling system (RAMS). Part I: Module description and supercell test simulations, J. Appl. Meteor., 43, 182-195, 2004.

Simpson, J. and Tao, W.-K.: The Goddard Cumulus Ensemble model. Part II: Applications for studying cloud precipitating processes and for NASA TRMM, Terr. Atmos. Ocean. Sci., 4, 73116, 1993.

Soong, S.-T. and Ogura, Y.: Response of trade wind cumuli to largescale processes, J. Atmos. Sci., 37, 2035-2050, 1980.

Spichtinger, P. and Gierens, K. M.: Modelling of cirrus clouds - Part 2: Competition of different nucleation mechanisms, Atmos. Chem. Phys., 9, 2319-2334, doi:10.5194/acp-9-2319-2009, 2009.

Tao, W.-K., Simpson, J., Baker, D., et al.: Microphysics, radiation and surface processes in the Goddard Cumulus Ensemble (GCE) model, Meteor. Atmos. Phys., 82, 97-137, 2003.
Tao, W.-K. and Simpson, J.: The Goddard Cumulus Ensemble model. Part I: Model description, Terr. Atmos. Ocean. Sci., 4, 19-54, 1993.

Twomey, S.: The influence of pollution on the shortwave albedo of clouds, J. Atmos. Sci., 34, 1149-1152, 1977.

Twomey, S.: Pollution and the Plantetary Albedo, Atmos. Environ., 8, 1251-1256, 1974.

Walko, R. L., Cotton, W. R., Meyers, M. P., and Harrington, J. Y.: New RAMS cloud microphysics parameterization: Part I. The single-moment scheme, Atmos. Res., 38, 29-62, 1995.

Wang, M., Penner, J. E., and Liu, X.: Coupled IMPACT aerosol and NCAR CAM3 model: Evaluation of predicted aerosol number and size distribution, J. Geophys. Res., 114, D06302, doi:10.1029/2008JD010459, 2009.

Wendisch, M., Yang, P., and Pilewskie, P.: Effects of ice crystal habit on thermal infrared radiative properties and forcing of cirrus, J. Geophys. Res., 112, D08201, doi:10.1029/2006JD007899, 2007.

Xu, K.-M, Richard, T. C., and Donner, L. J.: An intercomparison of cloud-resolving models with the Atmospheric Radiation Measurement summer 1997 Intensive Observation Period data, Q. J. Roy. Meteor. Soc., 128, 593-624, 2002. 